\title{
A ORGANIZAÇÃo FAMILIAR PARA O CUIDADO DOS FILHOS: PERCEPÇÃO DAS MÃES EM UMA COMUNIDADE DE BAIXA RENDA
}

Viviane Barrére Martin*

Margareth Angelo**

MARTIN, V.B.; ANGELO, M. A organização familiar para o cuidado dos filhos: percepção das mães em uma comunidade de baixa renda. Rev.latino-am.enfermagem, Ribeirão Preto, v. 7, n. 4, p. 89-95, outubro 1999.

Este estudo teve como objetivos compreender a percepção que mães de uma comunidade de baixa renda da cidade de São Paulo, têm sobre o significado do seu papel na estrutura familiar, em relação ao cuidado dos filhos e as estratégias utilizadas para desempenhar esse cuidado. A análise etnográfica nos possibilitou reconhecer 6 domínios culturais e resultados reveladores de que a mãe ocupa lugar central na família e é responsável pela educação, criação e socialização dos filhos. A adaptação do seu papel caracteriza-se pelo atendimento às necessidades de sobrevivência dos filhos, entretanto com o crescimento das crianças, demonstra insegurança frente à isso.

UNITERMOS: organização familiar, papel da mãe na família, famílias de baixa renda, método etnográfico

\section{INTRODUÇÃO}

Em estudo anteriormente realizado, em uma comunidade de baixa renda, identificamos que a mãe é a grande responsável pela saúde da família (MARTIN \& ANGELO,1996).

Isso nos indicou a necessidade de um aprofundamento no papel desempenhado pela mãe na estrutura familiar, por refletir aspectos da organização familiar, ou seja; a forma que a família divide suas responsabilidades entre os membros para cumprir o papel de educadora, provedora, cuidadora e socializadora dos filhos.

De acordo com LYNCH \& TIEDJE (1991), famílias pobres possuem características relativas à estrutura e papéis familiares, processos de comunicação familiar e socialização dos filhos, que são peculiares de sua classe. A divisão de papéis entre os pais é bem definida, cabendo à mulher a responsabilidade de educar, socializar e cuidar dos filhos e ao homem, o sustento da família. As interações entre pais e filhos visam à resolução de problemas e não à prevenção desses, ou seja; não há tomada de decisões antes que algo aconteça, há apenas a tentativa de solucionar um problema mediante sua concretização. Esse adiamento na resolução dos problemas acaba comprometendo o futuro dos filhos, pois não há planejamento do que irá acontecer com esses, as crianças já são predestinadas a falharem pela falta de perspectiva de futuro que lhes resta.

Outra característica, bastante peculiar, nessas famílias é a extrema aceleração no processo de formação de um casal, no casamento e nascimento dos filhos, o que segundo FULMER (1995), resultará na diminuição do tempo necessário que a família deveria ter para poder passar por todos os estágios do ciclo de vida familiar.

A rapidez dos acontecimentos pode trazer como consequência uma fragilidade no desempenho do papel dos pais, principalmente da mãe, por essa assumir grande parte dos cuidados para com os filhos pois de acordo com SUSSMUTH (1988), os homens recusam assumir ou participar mais ativamente do trabalho doméstico e da educação dos filhos, com o argumento de que são menos aptos para essas atividades e que lhes falta uma profunda relação com a criança. A mãe diante de todas essas responsabilidades, acaba desempenhando o seu papel de forma frágil, sem reflexão e à medida que os filhos crescem por não os ter preparado para o futuro, não dão conta de supervisioná-los como quando eram menores.

Conhecer o papel de cada membro e as vivências da família construídas ao longo de cada estágio de evolução em que passa, principalmente em se tratando

\footnotetext{
* Aluna do $4^{\circ}$ ano de Enfermagem da Universidade de São Paulo - Bolsista do CNPq-PIBIC

** Professora Doutora do Departamento de Enfermagem Materno Infantil e Psiquiátrica da Escola de Enfermagem da Universidade de São Paulo - Coordenadora do Projeto
} 
de famílias em situação de pobreza, por terem uma realidade bastante diferente, possibilita ao enfermeiro compreender como se dá a organização familiar, auxiliando o atendimento das demandas de cada um dos membros.

Segundo MOCCIA \& MASON (1986) o enfermeiro perante este quadro social, em face de sua posição como profissional de saúde, tem identificado a pessoa em situação de pobreza como um segmento da população, que resulta em grandes implicações para a assistência, o ensino e a pesquisa. Ter um embasamento teórico referente a todo o processo político-sócioeconômico de uma população, é importante para que se conheça a clientela que se irá assistir e para se entender o impacto que a pobreza traz para a saúde do indivíduo, tentando assim, auxiliá-los a adaptar-se e ajustar-se a ela reconhecendo suas possibilidades.

Diante disso, considerando a pobreza um fator que influencia diretamente a maneira como se dá o papel desempenhado pela mãe, no que diz respeito ao cuidado dos filhos e por essa refletir na organização familiar, estabelecemos como objetivos de nosso estudo:

- Compreender os significados para as mães, de seu papel na estrutura familiar e em relação ao cuidado dos filhos; - Compreender as estratégias utilizadas pela mãe na organização familiar, para cuidar dos filhos.

\section{METODOLOGIA}

A investigação foi desenvolvida segundo o enfoque qualitativo orientado pelo método etnográfico indicado por SPRADLEY (1980). O método consiste em uma abordagem que possibilita verificar como as pessoas vivem em seu ambiente natural e quais crenças e valores guiam os modos delas agirem em relação a algo. É um modo sistematizado de se apreender sobre determinada cultura.

Por ser a análise etnográfica uma proposta muito ampla, não se pretendeu nesse estudo utilizar todos os seus passos, mas apenas a questão etnográfica e os passos iniciais dessa análise.

\section{Coleta de dados}

O estudo foi realizado com mães de crianças residentes em uma comunidade de baixa renda localizada no município de São Paulo.

A coleta de dados se deu através de visitas domiciliárias a 10 dessas mães, sendo realizadas entrevistas abertas, semi-estruturadas tendo como questões norteadoras:
"Qual é o papel da senhora no cuidado dos filhos?"

"O que a senhora faz para desempenhar esse papel?”

Com o consentimento verbal das mães, as entrevistas foram gravadas, visando garantir o máximo de fidedignidade dos discursos.

A medida que considerasse necessário, o entrevistador acrescentava outras questões, para assim conseguir adquirir mais completamente indícios que promovessem o alcance dos objetivos propostos pela investigação.

Segundo ANGELO (1996); trabalhar com uma única questão norteadora, num estudo qualitativo, não significa que apenas esta questão fora formulada pelo pesquisador, significa que esta é a questão ponto de partida e a medida que, o pesquisador, considere necessário procurará formular novas questões para apreender o pensamento da pessoa.

Além dos dados relativos às experiências, foco do estudo, no decorrer da entrevista, sentiu-se necessidade de buscar informações, em relação ao número de filhos, idade, grau de instrução da mãe e demais indícios para se compor da melhor forma o perfil dessas mulheres em relação à constituição do ciclo de vida familiar.

\section{Análise dos dados}

Os depoimentos foram submetidos à análise etnográfica segundo SPRADLEY (1980). O processo consistiu em uma criteriosa leitura para que fosse possível a codificação dos dados buscando-se compreender o significado cultural dado pelo uso de símbolos na linguagem.

\section{Codificação}

As entrevistas gravadas foram transcritas na íntegra e após tal procedimento, o pesquisador realizou uma leitura criteriosa dos discursos. Tal leitura visa a apreensão dos significados contidos no texto, e resulta no agrupamento de informações de significados semelhantes ou códigos. Os códigos determinam a organização dos dados; à medida em que há leitura, o pesquisador destaca certas palavras, frases, formas dos informantes pensarem e agirem. Através da codificação dos dados, buscamos compreender o significado cultural, dado pelo uso de símbolos na linguagem, onde símbolo é o objeto ou evento que se refere a algo (ANGELO, 1996).

\section{Identificação de domínios culturais}

Cada código foi submetido a uma análise mais 
acurada, buscando a apreensão do significado contido naquele material agrupado. Este procedimento possibilitou a identificação dos domínios culturais, a primeira e mais importante unidade de análise na etnografia, por conter elementos essenciais ao conhecimento cultural.

Os domínios culturais encontrados nesses relatos expressam o papel da mãe na estrutura familiar e bem como as estratégias que utilizam para desempenhá-lo, isso composto a partir dos símbolos e referências identificados.

\section{RESULTADOS}

\section{CARACTERIZAÇÃO DAS MÃES ENTREVISTADAS}

IDADE:As idades compreendem 2438 anos, sendo que duas mães não souberam relatá-la.

GRAU DE INSTRUÇÃO: A maioria das mães relatou ter o ciclo básico do $1^{\circ} \mathrm{grau}$ incompleto $\left(1^{\circ}\right.$ e $2^{\circ}$ séries), uma única mãe referiu ser analfabeta e outra ter o $2^{\circ}$ grau em técnico de Contabilidade incompleto.

PROFISSÃO: A maioria das mães é dona de casa, uma mãe é dona de um bar, outra trabalha vendendo produtos de estética e costurando em sua casa e outra é faxineira.

ESTADO CIVIL: Todas as mães são casadas.

IDADE EM QUE TIVERAM $O 1^{\circ} \mathrm{FILHO}$ : Apenas uma mãe teve seu $1^{\circ}$ filho na adolescência, as demais tiveram entre 21 28 anos e duas mães não souberam relatar esse que stionamento.

CONSTITUIÇÃO DA FAMÍLIA DE ORIGEM DAS MÃES: A maioria era formada pela mãe, pai e irmãos. Apenas um caso era formado por mãe e irmãos devido o falecimento do pai e outro caso pela madrasta, pai e irmãos.

COM QUEM APRENDEU O PAPEL DE MÄE: A maioria das entrevistadas relatou que aprendeu com a própria mãe e dois casos relataram terem aprendido sozinhas

NÚMERO DE FILHOS: O número varia entre 2 e 6 filhos.

\section{Como definem família}

Para a cultura estudada, família é um conjunto de pessoas que vivem unidas, sem brigas e que tentam solucionar seus problemas e conflitos através do diálogo. Acreditam que a responsabilidade dos pais perante à criação e educação dos filhos, é a grande base que se pode ter para formá-la. A elaboração dessa definição é determinada pelos seguintes indicadores:

\section{É viver em harmonia}

"Familia é quando as pessoas se dão bem"

É ter união

"É as pessoas estarem unidas"

"Sem união não há família"

É ter diálogo

"É ter diálogo, todo mundo compreendendo mais

o outro"

É construir com responsabilidade

"É saber criar, educar e ir pelo pai e mãe"

\section{Como aprenderam o que é família}

Relatam que essa concepção de família se deu através dos meios de comunicação (programas de TV e rádio), do próprio dia a dia, da convivência e do diálogo com outras pessoas, vendo o comportamento de outras famílias e usando isso de exemplo, quando benéfico de forma a acrescentar algo positivo e quando maléfico, tentando não repetir o que notou.

\section{Com os meios de comunicação}

"Às vezes assistindo TV eles falam como lidar com a família"

"Com o programa do Paulo Barbosa"

\section{Com a própria família}

"Com os meus pais"

Vendo as outras pessoas

"A convivencia com os outros"

\section{Consigo mesma}

"Com o meu amadurecimento"

"Com o meu dia a dia"

\section{Como definem o seu dia}

O dia das mães é dedicado ao cuidar do outro, sobretudo dos filhos, do bem-estar familiar. Ela é a peça fundamental para que tudo corra de forma harmônica no dia de sua família. Seu dia contempla dentre outras coisas, acompanhar as crianças nas brincadeiras de rua, levá-las à escola, cuidar e higienizar a casa, preparar a alimentação de todos e às vezes, ainda trabalhar fora. Se trabalham, só saem para trabalhar quando as outras atividades da casa já estão realizadas e os filhos na creche, escola ou trabalho para assim não ter nada que atrapalhe o andamento das atividades de sua família, entretanto, valorizam muito seu emprego, porque com ele, conseguem auxiliar no orçamento familiar e melhorar um pouco a condição de vida de sua família.

\section{É acompanhar as crianças nas brincadeiras de rua}

"Vejo as crianças na rua porque é perigoso" 
É levar as crianças à escola

"Vou levar meu filho na creche"

"Levo o menino para a escola, volto e continuo o meu serviço"

\section{É cuidar/higienizar a casa para a família}

"Arrumo a casa"

"Limpo a casa"

\section{É cuidar da alimentação para a família}

"Faço comida"

"Dou janta para os meus filhos e marido"

\section{É cuidar da higiene da família}

"A tarde eu passo roupa"

"À tarde eu dou banho na minha filha"

\section{É trabalhar fora}

"Eu acho que mãe tem que trabalhar fora"

"Acho que mulher precisa trabalhar fora para ajudar porque eu fico em casa quando é 14:00 hs eu já fiz tudo"

"Meu emprego é bom, é gratificante"

"Imagina se eu não trabalhasse, com todos os problemas na cabeça”

\section{Como percebem o seu dia}

O cuidar da criação, educação dos filhos e da casa é visto como uma obrigação, algo inato, que só cabe à mulher realizar. Mesmo quando o homem tenta ajudála, considera que esse não tem habilidades para tanto e que já realiza a sua parte trabalhando fora.

\section{É cada um fazendo a sua parte}

"Pai ajuda mas não é como mãe para cuidar"

"A mãe tem obrigação porque pai tem que dar de comer, trabalhar fora e mãe fica com os filhos, cuidar, dá carinho"

\section{É o desempenhar de vários papéis}

"Mãe tem que cuidar da casa, dos filhos, dos afazeres domésticos"

"Dona de casa tem que cuidar da casa, dos filhos"

\section{É exaustivo}

"Eu acho que dona de casa trabalha muito"

"Tem sempre coisa para fazer, eu não paro o dia todo"

"Dou uma descansadinha depois do almoço"

\section{Como definem o dia dos filhos}

O dia dos filhos é caracterizado de acordo com a fase de desenvolvimento em que esses se encontram. As crianças menores e em idade pré-escolar passam grande parte do dia ao lado das mães, recebendo os cuidados maternos. Quando não estão com as mães, estão na creche ou escolinha. As crianças em idade escolar, ficam mais sozinhas, preferem brincar na rua, vão à escola. Os adolescentes trabalham e alguns também estudam, passam a maior parte do dia fora de casa.

\section{É estudar e trabalhar}

"O menino passa a maior parte do dia na Creche"

"O mais velho acorda e vai para o SENAI"

\section{É ficar na rua}

"Meu pequenininho estuda e a tarde está sem atividades, então ele fica na rua"

"Eles ficam o dia todo na rua, eu tenho que ficar olhando toda hora"

\section{É ajudar em casa}

"Às vezes meu pequenininho me ajuda em casa, limpa o banheiro"

\section{É brincar/comer/dormir}

"Volta da escola, vai ver $T V$, às vezes adianta a lição, janta, fica vendo TV e vai dormir"

"Quando ele chega da creche deixo ele brincar um pouquinho, depois dou banho e 22:30 hs ponho dormir"

\section{Como percebem o dia dos filhos}

Avaliam o dia dos filhos também de acordo com a fase de desenvolvimento em que se encontram. Acreditam que as crianças menores e pré-escolares possuem um dia normal para suas idades, realizam tarefas típicas de crianças, permanecem ao lado das mães por dependerem de seus cuidados.

Os filhos em idade escolar são mais independentes das mães, querem mais liberdade, começam a "desafiá-las" para poderem brincar na rua, saírem sozinhos. Isso chega a incomodar as mães, por não terem muita disponibilidade de acompanhá-los e terem que às vezes, deixar suas tarefas domésticas para vigiá-los. Com isso, consideram que o dia desses deveria ser melhor ocupado porque se estivessem com outras atividades além da escola, não estariam nas ruas. Teriam assim, alguém que ainda os controlasse e assumisse o papel que essas já não conseguem mais desempenhar.

Já os adolescentes, por serem mais velhos, não estão sobre o controle das mães, ou seja; essas já não conseguem administrar suas vidas como fazem com os menores, se sentem impotentes diante deles, é como se o futuro fosse encaminhá-los para elas. 
Deveriam ocupá-lo melhor

"Eu queria que eles trabalhassem mas até hoje não deu”

"Eu queria que eles estivessem na escola, lá estão assegurados"

\section{Vivem como crianças}

"O que eles fazem está certo, brinca, vê TV, criança precisa de tudo um pouquinho"

"São crianças muito boas, não dão um pingo de trabalho"

\section{DISCUSSÃO}

Ainda hoje, é muito freqüente ligar-se maternidade à atividade na família e opô-la a características como competência especializada, capacidade de se impor, capacidade de concorrência e engajamento profissional. Em vez de dominar tarefas específicas, as mães devem é educar seus filhos. Segundo essa concepção, a tarefa da mãe, conforme a sua natureza e o seu destino de mulher, é ocupar-se das pessoas da família, cultivar relações e ser espontânea, calorosa, sensitiva, suave e abnegada. Seu campo principal de atuação não é a profissão e sim, o cultivo e o desenrolar da vida humana (SUSSMUTH, 1988).

Sendo as famílias de nosso estudo compostas pela mãe, pai e filhos, a organização familiar para o cuidado desses se dá entre a mãe e o pai, tendo ambos papéis bem definidos. O pai se responsabiliza pelo sustento da família, nesse caso, o de subsistência e a mãe se encarrega de todos os outros papéis para com as crianças e com o marido.

Diante, do que lhe foi ensinado por seus pais e reforçado com os comportamentos de sua mãe, considera seu desempenho uma obrigação, algo dado à mulher de forma inata e acredita que o seu marido ou companheiro já faz a sua parte trabalhando para dar de comer aos seus filhos, não tendo que ter mais a obrigação de auxiliá-la na educação e cuidado das crianças, pois esse é seu papel dentro da estrutura familiar.

Assim, a mulher acaba repetindo o mesmo ciclo de vida de sua mãe e das mulheres de sua família. Quando criança não se dedica muito aos estudos já que irá se casar e desenvolver a sua habilidade de mãe, à medida em que vai amadurecendo vai assumindo mais autoridade e responsabilidade no seu cuidar. O casamento é visto como o destino de toda mulher, ela nasce e desde então, já começa a se preparar para ele. Ainda pequena, vai aprendendo com sua mãe as tarefas maternas que mais tarde terá que desempenhar para sua futura família.

A mulher-mãe torna-se o eixo da estrutura familiar, tudo passa a ser alvo de seu controle: a criação e educação dos filhos, o cuidado com a casa, com a saúde dos membros da família. A expectativa que se tem dela e que ela tem de si mesma é a de cuidadora, como se ela nascesse com essa habilidade e capacidade a desenvolver.

Todavia, sendo essa a responsabilidade da mãe, ela acaba criando estratégias para poder contemplar o seu papel na organização familiar. Dentre essas estratégias, podemos citar a adequação do horário de trabalho da mãe, seja ele doméstico ou não, às necessidades e atividades dos filhos, à rotina doméstica girando também em torno dessas necessidades, a desistência do emprego, quando possível, a favor das demandas dos filhos.

O bom desempenho materno é cobrado pela sociedade, porém as mães, de nosso estudo, apesar de perceberem a importância do seu papel, parece que o desempenham com pouca reflexão. Tudo o que realizam é representado de forma "mecânica" como: levar o filho à escola, dar comida, dar banho, decidir sobre deixá-lo ou não ir à rua, etc, reproduzindo ações aprendidas em sua família de origem ou em sua atual vivência.

A este respeito, GOMES (1994) observa que a família transmite às novas gerações, especialmente à criança, desde o nascimento, padrões de comportamento, hábitos, usos, costumes, valores, atitudes e um padrão de linguagem. Enfim, maneiras de pensar, de se expressar, de sentir, de agir e de reagir que lhe são próprias, naturais. Promove ainda a construção das bases da subjetividade, da personalidade e da identidade. Segundo o autor, nessas características resulta a enorme importância da família tendo em vista a vida futura de cada criança: ou seja a família, constrói os alicerces do adulto futuro.

Neste estudo, vimos que a socialização, que cabe à mãe nessas famílias, é transmitida aos filhos sem uma reflexão profunda. O papel dela na cultura estudada pode ser descrito como algo que representa força e fragilidade ao mesmo tempo, pois desempenha um papel que escolheu, mas é vulnerável a esse, devido à falta de oportunidade que teve em aprendê-lo.

Essa vulnerabilidade da mãe é demonstrada à medida que a criança vai crescendo. Segundo os relatos das mães entrevistadas, os filhos mais velhos já não dão satisfação do seu dia e a desafiam para conseguir o que almejam. A mãe se torna impotente, frente a seu próprio filho, e nesse momento, desiste esperando que outras pessoas e que o próprio destino se encarregue do futuro desse.

Os relatos das mães deste estudo, são semelhantes aos apresentados por FULMER (1995) acerca de famílias de baixa renda. O autor refere que mães com estas características conseguem cuidar e supervisionar seus filhos até a faixa etária da pré-adolescência. A partir desse período consideram que os perderam para o mundo pouco 
confiável e incontrolável dos adultos. Deixam de esperar que eles sejam responsáveis e fazem poucas tentativas de influenciá-los, desta forma, também perdem o contato íntimo com eles.

Diante dessas evidências, se tomarmos as palavras de GOMES (1994) de que tornar a criança um ser social é torná-la um membro típico de uma classe específica, em uma estrutura social objetiva e ampla, mas antes de tudo, de classes, podemos dizer que a maneira frágil como as mães deste estudo desempenham seu papel, pode também tornar frágil o processo de socialização dos seus filhos. A socialização não pode ser considerada papel exclusivo da mulher nem tampouco obrigação da família, no caso de famílias em situação de baixa renda, pois essas já vivem um quinhão diário de pobreza e de opressão, não podendo arcar com a responsabilidade da construção do futuro de seus filhos.

\section{CONSIDERAÇÕES FINAIS}

Não podemos negar que a forma com que a mãe desempenha o seu papel nas famílias de baixa renda é algo decorrente de uma série de fatores sócio-econômicos e que identificar a base sociocultural da família, é primordial para a compreensão de comportamentos e valores relacionados à criação e educação dos filhos, isso porque as pressões ambientais que sofrem indivíduos em situação de pobreza, são em grande parte responsáveis pelos transtornos no desenvolvimento da criança, por requerer súbitas mudanças na estrutura familiar.

Se para as mulheres de nosso estudo a sua realização está no papel de mãe e ao mesmo tempo é revelada a sua vulnerabilidade nesse papel, cabe ao enfermeiro a tentativa de intervenção perante essa necessidade identificada, fortalecendo-a para o desempenho de seu papel na família. É um aspecto da atuação de enfermagem na assistência à família que não somente provoca mudanças no papel atual da mulher na família, mas consiste em possibilidade de transformar o futuro de outras mulheres, que hoje são filhos nestas famílias.

Numa perspectiva de assistência à família, este estudo gerou algumas indagações, destinadas ao aprofundamento desta área essencial à saúde da própria sociedade.

O quanto as mães percebem a necessidade de adaptar seu papel às mudanças no ciclo de vida familiar e ainda assim continuarem exercendo sua responsabilidade?

Como a dinâmica familiar se processa em decorrência do desenvolvimento de cada membro da família?

O quanto os pais estão preparados para desempenhar o seu papel?

O quanto é necessário em um enfoque de saúde familiar, capacitar a mãe a exercer sua necessidade de cuidadora?

\section{FAMILY ORGANIZATION REGARDING CHILDREN CARE: MOTHERS PERCEPTION IN A LOW INCOME COMMUNITY}

The purposes of this study are to understand the perception that the mothers from a low income community in São Paulo city have about the meaning of their role in the family structure, concerning children care and the strategies used in family organization to carry out this care. The ethnographic analysis allowed us to identify 6 cultural domains and results showed that the mother have a main role in the family. They are the great responsible for the education, raising and socialization of the children. The adaptation of their role is characterized by their attention regarding to children needs. However, when they face children's growth, they show insecurity.

KEY WORDS: family organization, mother's role in the family, low income families, ethnographic method

\section{LA ORGANIZACIÓN FAMILIAR PARA EL CUIDADO DE LOS HIJOS: PERCEPCIÓN DE LAS MADRES EN UNA COMUNIDAD DE BAJA RENTA}

El estudio tuvo como objetivos comprender la percepción que madres de una comunidad de baja renta de la ciudad de São Paulo tienen sobre el significado de su papel en la estructura familiar, con relación al cuidado de los hijos y las estrategias que utilizan para desempeñar ese cuidado. El análisis etnográfico posibilitó reconocer 6 dominios culturales y resultados reveladores de que la madre ocupa lugar central en la familia, es responsable por la educación, crianza y socialización de los hijos. La adaptación de su papel se caracteriza por el cubrimiento de las necesidades de supervivencia de los hijos, pero con el crecimiento de los hijos la madre demuestra inseguridad en su desempeño.

TÉRMINOS CLAVES: familias de baja renta, papelde la madre, cuidado con los hijos, análisis atnográfico, organización familiar 


\section{REFERÊNCIAS BIBLIOGRÁFICAS}

01. ANGELO, M. Análise de dados qualitativos. São Paulo: EE-USP, 1996. /Mimeografado/.

02. FULMER, R.H. Famílias de baixa renda e famílias com formação profissional: uma comparação da estrutura e do processo de ciclo de vida. In: CARTER, B.; McGOLDRICK, M. As mudanças no ciclo de vida familiar: uma estrutura para a terapia familiar. Porto Alegre, 1995. cap. 22, p. 468-95.

03. GOMES, J.V. Socialização primária: tarefa familiar? Cad.Pesq., São Paulo, n. 91, p. 54-61, nov.1994.

04. LYNCH, I.; TIEDJE, L.B. Working with multiproblem families in intervention model for community helth nurses. Public Health Nurs., v. 8, n. 3, p. 147-153, 1991.

05. MARTIN, V.B.; ANGELO, M. O significado do conceito saúde na perspectiva de famílias em situação de risco pessoal e social. São Paulo, 1996. /Mimeografado/.

06. MOCCIA, P.; MASON, D.J. Poverty trends: implications for nursing. Nurs.Outlook., v. 6,n. 4, p. 197-203, 1986.
07. SPRADLEY, J.R. Participant observation. New York: Wolt, Rinehalt and Winston, 1980. 195p.

08. SUSSMUTH, R. A nova maternidade e os projetos de vida da mulher. In: SOLIZ, N. A mulher no séc. XXI: um estudo de caso, a Alemanha. São Paulo: Instituto Goethe, 1988.

\section{BIBLIOGRAFIA CONSULTADA}

01. MACEDO, R.M. A família do ponto de vista psicológico: lugar seguro para crescer? Cad.Pesq., São Paulo, n. 91, p. 62-8, nov.1994.

02. McGOLDRICK, M. As mulheres e o ciclo de vida familiar. In: CARTER, B.; McGOLDRICK, M. (org). As mudanças no ciclo de vida familiar: uma estrutura para a terapia familiar. Porto Alegre, 1995. cap. 2, p. 30-60.

03. SARTI, C.A. A família como ordem moral. Cad.Pesq., São Paulo, n. 91, p. 46-53, nov. 1994.

04. ZERWEKH, J.V. Laying the groundwork for family self-help: locating families, building trust, and building strengh. Public Health Nurs., v. 9, n. 1, p. 15-21, 1992. 